\title{
Influence of Pattern Acquisition Way on Individual's Pattern Recognition in Solving Different Kinds of Mathematical Problems
}

\author{
Wenhua $\mathrm{Yu}$ \\ Department of Mathematics \\ Shandong Normal University \\ Jinan, China \\ sdnuywh@126.com
}

\begin{abstract}
The factors (Pattern Acquisition Way, Problem Type and Pattern Quality) in solving different kinds of mathematical problems were studied. It was found that acquisition way and problem type significantly influence pattern recognition, and their interaction influences pattern recognition significantly. Acquisition way significantly influences pattern quality, which significantly influences pattern recognition.
\end{abstract}

Keywords-Pattern Acquisition Way; Pattern Recognition; Problem Types

\section{INTRODUCTION}

Many researches cared about mathematical problem solving and categorization $[1,2,3,4,5]$.In this study, we preferred to measure participants' template quality by source problem recalling and problem composing, to explore the different acquisition ways' influence on individual's template quality, and to explore how different problem types affect pattern recognition in solving problems.

\section{METHOD}

\section{A. Subjects}

The subjects were 62 students in a senior school at Jinan, China. Subjects were randomly divided into two groups. Subjects were tested in class several weeks after the beginning of the summer quarter.

\section{B. Test}

The test included three source problems (see TABLE I ) and eight target problems(see TABLE II), which were all arrangement problems.

TABLE I. SOURCE PROBLEMS

\begin{tabular}{|c|c|}
\hline $\begin{array}{c}\text { Problem } \\
\text { Type }\end{array}$ & Problems \\
\hline $\begin{array}{c}\text { adjacent } \\
\text { problem }\end{array}$ & $\begin{array}{c}\text { (A) Five people named a, b, c, d, e stand in a row, but } \\
\text { a and b must be adjacent. How many different ways } \\
\text { of standing? }\end{array}$ \\
\hline $\begin{array}{c}\text { non- } \\
\text { adjacent } \\
\text { problem }\end{array}$ & $\begin{array}{c}\text { (B) Five people named a, b, c, d, e stand in a row, } \\
\text { but a and b must be non-adjacent. How many } \\
\text { different ways of standing? }\end{array}$ \\
\hline $\begin{array}{c}\text { location } \\
\text { problem }\end{array}$ & $\begin{array}{c}\text { (C) One teacher and four students stand in a row, but } \\
\text { the teacher must not stand at neither side. How many } \\
\text { different ways of standing? }\end{array}$ \\
\hline
\end{tabular}

\section{Design}

Two factors mixed design was used in this research. The first factor is Pattern Acquisition Way, which has 2 levels, that is pattern structure study, pattern ordinary study. The second factor is Problem Types, which has 3levels, that is, homotype problem, variant problem, cross problem. Pattern Acquisition Way is between-subject factor, and Problem Types is within-subject factor.

\section{Procedure}

First stage: source problem studying. The two groups of subjects were tested in two classrooms. Pattern structure study group studied how to solve the three source problems and the teacher emphasized the structure and the strategy of the problems. In detail, when students were learning the adjacent problem, the strategy "tie up" and Figure 1 were shown to the subjects. When students were learning the nonadjacent problem, the strategy "interpolate" and Figure.2 were shown to the subjects. When students were learning the location problem, the strategy "prior" and Figure 3 were shown to the subjects. Pattern ordinary study studied how to solve the three source problems without the structure and the strategy of the problems.

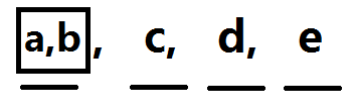

Figure 1. Adjacent Problem Strategy

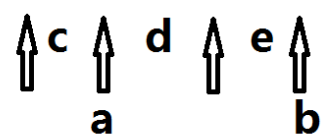

Figure 2. Non-adjacent Problem Strategy

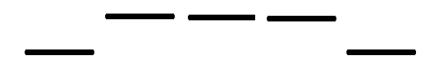

Figure 3. Location Problem Strategy 
TABLE II. Target Problems

\begin{tabular}{|c|c|c|}
\hline \multicolumn{2}{|c|}{ Problem Type } & Problems \\
\hline \multirow{3}{*}{$\begin{array}{l}\text { homotype } \\
\text { problem }\end{array}$} & $\begin{array}{l}\text { adjacent } \\
\text { problem }\end{array}$ & $\begin{array}{l}\text { (A1) Five students and three teachers stood a } \\
\text { row of photography, but three teachers must be } \\
\text { adjacent. How many different ways of } \\
\text { standing? }\end{array}$ \\
\hline & $\begin{array}{l}\text { non- } \\
\text { adjacent } \\
\text { problem }\end{array}$ & $\begin{array}{l}\text { (B1)A program with six songs and four dances } \\
\text { is to be arranged, but any two dances are not } \\
\text { adjacent. How many different ways of } \\
\text { arranging? }\end{array}$ \\
\hline & $\begin{array}{l}\text { location } \\
\text { problem }\end{array}$ & $\begin{array}{l}\text { (C1) Two officers and five soldiers stood in a } \\
\text { row, but the officers are not in the side. How } \\
\text { many different ways of standing? }\end{array}$ \\
\hline \multirow{3}{*}{$\begin{array}{c}\text { variant } \\
\text { problem }\end{array}$} & $\begin{array}{l}\text { adjacent } \\
\text { problem }\end{array}$ & $\begin{array}{c}\text { (A2) Eight athletes of a class lined up } \\
\text { photography as a souvenir after sports meeting, } \\
\text { if athlete a and athlete b must have one } \\
\text { between them. How many different ways of } \\
\text { standing? }\end{array}$ \\
\hline & $\begin{array}{l}\text { non- } \\
\text { adjacent } \\
\text { problem }\end{array}$ & $\begin{array}{l}\text { (B2) In a schedule, there are eight programs. } \\
\text { Now three programs are to be added with } \\
\text { maintaining the relative order of the original } \\
\text { programs. How many different ways of } \\
\text { arranging? }\end{array}$ \\
\hline & $\begin{array}{l}\text { location } \\
\text { problem }\end{array}$ & $\begin{array}{l}\text { (C2) Five children line up. Jack likes to stand } \\
\text { in the end or the first, Linda don't like to stand } \\
\text { in the end or the first. How many different } \\
\text { ways of arranging with meeting the } \\
\text { requirements of they both? }\end{array}$ \\
\hline \multirow{2}{*}{\multicolumn{2}{|c|}{ cross problem }} & $\begin{array}{l}\text { (AB)Jack, grandpa, grandma, father, and } \\
\text { mother stand in a row. Jack and grandma will } \\
\text { be next to each other, but grandpa and mother } \\
\text { won't be next to each other. How many } \\
\text { different ways of arranging? }\end{array}$ \\
\hline & & $\begin{array}{l}\text { (AC) Ten different pictures are to be showed, } \\
\text { one watercolor painting, four oil painting, and } \\
\text { five traditional Chinese painting will be lined } \\
\text { up on display. But the same varieties of } \\
\text { paintings must be together, and watercolor } \\
\text { painting cannot be placed on both ends. How } \\
\text { many different ways of arranging? }\end{array}$ \\
\hline
\end{tabular}

Second stage: source problem recalling and problem composing. After studying source problems, each subject was asked for recalling the source problems and composing new problems of three types.

Third stage: target problems solving. Each subject was given 15 minutes to solve the target problems.

\section{RESULTS}

\section{A. Pattern Quality}

For source problem recalling, the subject with good pattern got 2 scores, normal pattern ones got 1 scores, and bad pattern ones got 0 scores. For problem composing, every right problem got 2 scores, half-considered problem got 1 scores and the others got 0 scores. The sum score of the source problem recalling and problem composing was the score of pattern quality. The results were shown in TABLE III.

T-test showed that the two groups had a very significant difference $(\mathrm{t}=5.17, \mathrm{p}=0.000)$ in the template quality. There is significant difference $(\mathrm{t}=5.40, \mathrm{p}=0.000)$ in source problem recalling and $(\mathrm{t}=3.82, \mathrm{p}=0.000)$ in problem composing.

\section{TABLE III. SCORES ON SOURCE PROBLEM RECALLING, PROBLEM COMPOSING, PATTERN QUALITY (MEAN \pm STANDARD DEVIATION)}

\begin{tabular}{|c|c|c|c|}
\hline Groups & $\begin{array}{c}\text { Source } \\
\text { Problem } \\
\text { Recalling }\end{array}$ & $\begin{array}{c}\text { Problem } \\
\text { Composing }\end{array}$ & $\begin{array}{c}\text { Pattern } \\
\text { Quality }\end{array}$ \\
\hline $\begin{array}{c}\text { pattern } \\
\text { structure study }\end{array}$ & $3.94 \pm 0.68$ & $3.90 \pm 0.79$ & $7.84 \pm 1.27$ \\
\hline $\begin{array}{c}\text { pattern ordinary } \\
\text { study }\end{array}$ & $3.00 \pm 0.68$ & $3.13 \pm 0.81$ & $6.13 \pm 1.34$ \\
\hline $\mathrm{t}$ & 5.40 & 3.82 & 5.17 \\
\hline $\mathrm{p}$ & 0.000 & 0.000 & 0.000 \\
\hline
\end{tabular}

There is very significant difference in source problem recalling between pattern structure study group and pattern ordinary study group, which indicated pattern structure study group has more in-depth understanding on the source problems, and greater using the source problems in solving the target problems.

\section{B. Pattern Recognition Coding}

As the same method of [5], according to the students' actual performance on target problems, we put pattern recognition into three categories: successful pattern recognition, half pattern recognition, and no pattern recognition.

\section{Pattern Recognition Dependent on Pattern Acquisition Way and Problem Types}

First of all, the subjects' pattern recognition results are shown in TABLE IV:

TABLE IV. THE PATTERN RECOGNITION RESULTS OF TWO GROUPS (MEAN \pm STANDARD DEVIATION)

\begin{tabular}{|c|c|c|c|c|}
\hline Groups & $\begin{array}{c}\text { Homotype } \\
\text { Problem }\end{array}$ & $\begin{array}{c}\text { Variant } \\
\text { Problem }\end{array}$ & $\begin{array}{c}\text { Cross } \\
\text { Problem }\end{array}$ & $\begin{array}{c}\text { Pattern } \\
\text { Recognition }\end{array}$ \\
\hline $\begin{array}{c}\text { pattern } \\
\text { structure } \\
\text { study }\end{array}$ & $3.90 \pm 0.65$ & $3.49 \pm 0.77$ & $3.61 \pm 0.76$ & $11.00 \pm 1.90$ \\
\hline $\begin{array}{c}\text { pattern } \\
\text { ordinary } \\
\text { study }\end{array}$ & $2.84 \pm 0.64$ & $2.87 \pm 0.72$ & $2.87 \pm 0.67$ & $8.58 \pm 1.80$ \\
\hline
\end{tabular}

Second, groups with different Pattern Acquisition Way on pattern recognition are compared. $T$ test showed that the two groups had significant differences on the pattern recognition results $(t=5.15, p=0.000)$, very significant differences on homotype problem $(t=6.51, p=0.000)$, very significant differences on variant problem $(\mathrm{t}=3.24, \mathrm{p}=$ 0.002 ), and very significant differences on cross problem ( $\mathrm{t}$ $=4.07, \mathrm{p}=0.000$ ).

Third, with each group's pattern recognition as a dependent variable, two-factors-mixed-design analysis of variance was done for repeated measuring one factor (see TABLE V). The results showed that the main effect of the acquisition ways was very significant $(\mathrm{F}=26.483, \mathrm{P}=$ $0.000<0.001$ ), and results of the pattern structure studying subjects $(11.00 \pm 1.90)$ is much better than that of pattern 
ordinary studying subjects $(8.58 \pm 1.80)$. Main effect of problem types was significant $(\mathrm{F}=3.53, \mathrm{P}=0.032<0.05)$. Interaction of problem types and acquisition ways was significant $(\mathrm{F}=4.921, \mathrm{P}=0.009<0.01)$.

TABLE V.VARIANCE ANALYSIS OF PATTERN RECOGNITION RESULTS UNDER DIFFERENT EXPERIMENTAL CONDITIONS

\begin{tabular}{|c|c|c|c|c|}
\hline Source of variation & square & df & mean & value of $\mathrm{F}$ \\
\hline $\mathrm{PA}^{\mathrm{a}}(\mathrm{A})$ & 30.242 & 1 & 30.242 & $26.483 * *$ \\
\hline $\mathrm{PT}^{\mathrm{b}}(\mathrm{B})$ & 1.204 & 2 & .602 & $3.533^{*}$ \\
\hline $\mathrm{A} \times \mathrm{B}$ & 1.677 & 2 & .839 & $4.921 * *$ \\
\hline
\end{tabular}

${ }^{\mathrm{b}}$ Problem Types

From Figure 4, we can see that pattern recognition of subjects under the condition of pattern structure studying was significantly higher than that of the subjects under the condition of pattern ordinary studying.

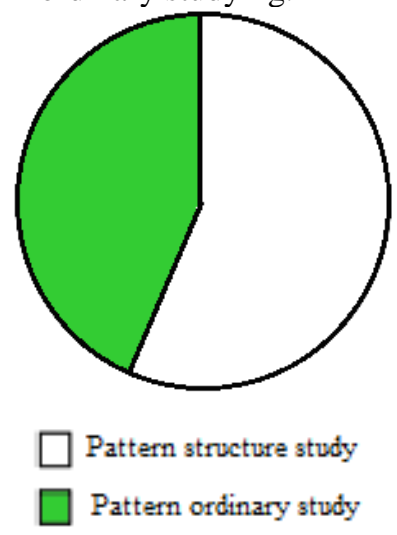

Figure 4. Acquisition way 's influence on the pattern recognition result

It's showed in Figure 5 that the problem type influencing pattern recognition mainly reflected in the difference between homotype problem and variant problem, and the difference between homotype problem and cross problem. Further single factor variance analysis found that, the homogeneity of variance test $(p=0.058>0.05)$ meant the variance was homogenate. LSD test found that the difference between homotype problem and variant problem was significant $(\mathrm{p}=.017<0.05)$, there does not exist significant differences between homotype problem and cross problem $(\mathrm{p}=.088)$, or between variant problem and cross problem $(\mathrm{p}=.398)$.

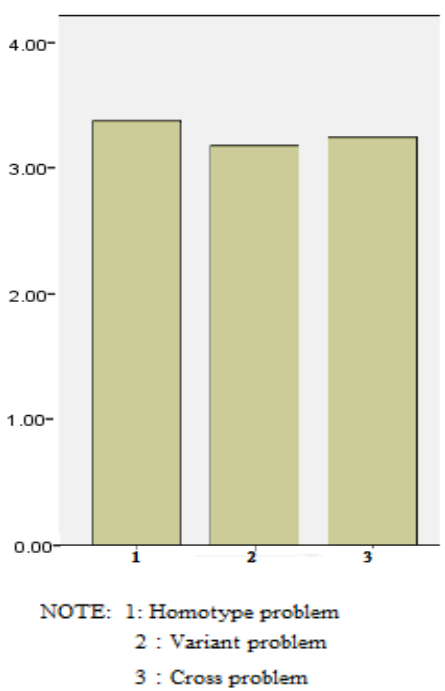

Figure 5. Pattern recognition scores on different problems

Diagram mapping out the interaction of the two factors on pattern recognition were shown in Figure 6. We can see that, trends of the factor acquisition ways affecting pattern recognition on three levels of problem types were not the same. The difference between pattern structure studying group and pattern ordinary studying group on homotype problem was much higher than the difference on cross problems, which was much higher than that on variant problems.

This showed that, for homotype problem and cross problems, structure studying would improve their pattern recognition. For variant problems, the effect was not very obvious.

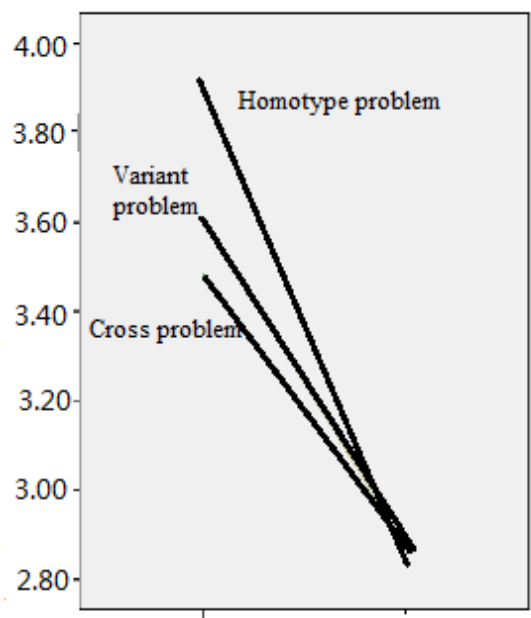

Pattern structure study Pattern ordinary study

Figure 6. The Interaction of acquisition way and problem type

\section{Dependence on the Quality of Template Pattern Recognition Results}

The bar chart showing the template quality's influence on pattern recognition of different problem types were shown in Figure 7. We can see from the figure, with the 
improvement of pattern quality, pattern recognition of three problem types showed the general trend of increasing. That suggests the pattern quality directly relates to the success or failure of pattern recognition.

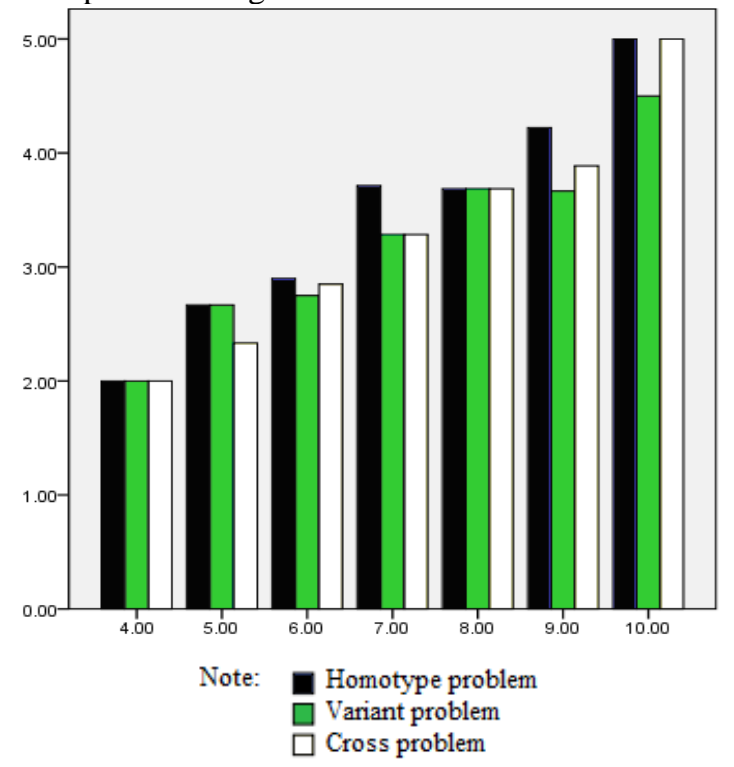

Figure 7. recognition scores of the three problem types under different pattern quality

\section{DISCUSSION}

\section{A. Structure Studying Improving the Pattern Quality}

Experiments showed that the difference of pattern acquisition ways led to the difference in pattern quality. The symbolization, visualization and "visualization" of the strategy's name under structure studying mode all further improved the learners' cognitive and deep understanding of patterns, which made pattern quality significantly better than that of general learning. That suggests the importance of acquisition way in our teaching.

\section{B. The Influencing Factors of Pattern Recognition}

1) Pattern Quality: Pattern quality directly affects the recognition results. Pattern recognition is the process of best matching the current problems to the patterns in one's cognitive structure, so the rationality of the matching depends directly on the pattern quality, which was proved by the experimental results very well.

2) Acquisition Way: Acquisition way directly affects the pattern quality, and pattern quality directly affects the pattern recognition, so acquisition way will inevitably affect the pattern recognition. The experimental results proved the conclusion well.

3) Problem Type: To different types of problems, difficulty of pattern recognition should be different. For homotype problems, identifying situation, seizing the essence of the problem, and expecting something according to the specific context information altogether can achieve pattern matching. For variant problems, processing objects, clearing structure and fixing patterns which need the necessary adjustment and transformation process are bound to be more complicated than pattern recognition process of homotype problems. For cross problems, pattern recognition which needed integrating kinds of patterns, evaluating and adjusting of the figure is not in the same level with homotype problems.

This study found that the problem type significantly influences students' pattern recognition in problem solving. Homotype problems were most easily to identify, cross problems were easier to identify, and variant problems were the most difficult to identify. And the result has, of course, some relations with the choice of materials. In this study, cross problems are not difficult to solve, but it needs more variant of adjustment and transformation to solve variant problems. So the diversity of cross problems is likely to lead to the differences of different research conclusion.

\section{ACKNOWLEDGMENT}

This work is supported by Ministry of Education Humanities and Social Science Research Youth Foundation Grant \#10YJCXLX054 to Yu Wenhua

\section{REFERENCES}

[1] L.S.Fuchs, K.Prentice, "Enhancing mathematical problem solving among third-grade students with schema-based instruction", Journal of Educational Psychology, vol.96, pp. 635-647, 2004.

[2] M.H.Chi, J.Felt, R.Glaser, "Categorization and representation of physics problems by experts and novices", Cognitive Science, no.5,pp.121-152, 1981.

[3] J.D.Smith, J.P.Minda. "Prototypes in the mist: The early epochs of category learning", Journal of Experimental Psychology: Learning, Memory, and Cognition, vol. 24, no. 6,pp.1411-1436,1998.

[4] J.Clement, "Algebra word problem solutions: Thought processes underlying a common misconception",.Journal for Research in Mathematics Education, no.13,pp.16-30,1982.

[5] R.Laura, Novick, J.Keith, Holyoak, "Mathematical Problem Solving by Analogy", Journal of Experimental Psychology:Learning, Memory, and Cognition, vol. 23, no. 3, pp. 398-415, March 1991. 